\title{
Contemporary Native American realities: in search of literary and cultural sovereignty
}

\author{
Sanja Runtić ${ }^{1}$ - Marija Krivokapić ${ }^{1}$. \\ Timothy Petete $^{1} \cdot$ Neil Diamond $^{1}$
}

Published online: 20 March 2017

(C) Akadémiai Kiadó, Budapest, Hungary 2017

On June 25-27, 2015, at the Faculty of Philosophy of the University of Montenegro, we organized an international conference titled Contemporary Indigenous Realities. Defining realities as attributes and circumstances that shape one's perspective, we focused our scope on twenty-first century phenomena related to indigenous peoples and received contributions from a variety of disciplines including literature, cultural and ethnic studies, anthropology, and arts. This volume, however, presents only the research dealing with Native American issues.

The story about contemporary Native American literary achievement cannot begin without problematizing the often painful issue of identity. In the first place, we have to ask what Native American literature is, if it is a piece of writing made by Native Americans exclusively, regardless of the topic, or a piece of writing about Native Americans, despite of its author's origin, if the Native American topics are genuine, or whether it is their exoticity that ensures their presence in the literary market to suit editors' tastes. To answer those questions, we are led to another, more disturbing, set of debates related to the presence of Native American subjects in contemporary North American reality and their historical subjugation to numerous political and narrative marginalization strategies.

To enable a solid ground from which to assess contemporary Native American realities-yet without an attempt to issue a political judgment or essentialize any party in the ongoing debate-we have chosen to open this volume with a group of articles discussing the burning identity problems that have powerfully affected contemporary Native American literary, art, and media expression and representation, as well as production in general. Every article strictly focused on literary matters in this volume suggests that to talk about Native American literature today necessarily means to trace its quest for cultural and rhetorical sovereignty, be it

Marija Krivokapić

marija13a@gmail.com

1 Faculty of Philology, Danila Bojovica bb, Niksic 40000, Montenegro 
through the images explored or the narrative manoeuvres employed. For this purpose, we will first problematize the dominant culture's narrative of exclusion and misappropriation through exploration of its set of, mostly insulting, images, and then we will proceed to their literary elaborations in the works of some of the leading Native American authors, such as Louise Erdrich, Thomas King, Rudy Wiebe, and Sherman Alexie.

The opening article, "The over-consumption of Native American imagery and the ongoing results," by Daniel Green from the University of Wisconsin-La Crosse, United States, observes more than one hundred popular images of Native American subjects whose patterns include primitivism, savagery, sex objectification, buffoons, anachronisms, and stereotypes. The prevalence of these images can be found in commercialism, sports, movies and television, literature and magazines, toys, the military, and endless entertainment celebrities dressed as Native Americans. Green argues that the popular Pocahontas myth and Cooper's The Last of the Mohicans, the cult novel that celebrates the Manifest Destiny, might have been the instances that instigated the insurgence of these reified images and examines the "cause and effect" of this indigenous phenomenon that is ubiquitous worldwide. The misinformation, lies, stereotypes, and myths about Native Americans have resulted in imagery, held by both Natives and non-Natives, that is archaic at best and psychologically harmful at worst. This (mis)perception of indigenous peoples has become American schema due to pervasive and myth-borne legacy. Green relies on scholars from the fields of literature, sociology, and social psychology who have measured the effects of related oppressive societal qualities, always with the results harming the psyche of those so poorly portrayed.

Along the same line, Sanja Runtić and Luka Pejić from the University of Osijek, Croatia, discuss the ongoing debate over "Washington Redskins" name and imagery. Their paper, "NO LOGO!: Visual sovereignty and the Washington Redsk*ns debate," draws upon the controversy over the use of indigenous-related sports emblems that has recently sparked a series of protests across the United States. It focuses on the visual aspect of the debate, tracing the white-supremacist foundations of the Washington team's insignia to the institutional construction of Native identity through popular Indian head pennies, gold coins, and buffalo nickels in the period between 1859 and 1938. Pointing to the seemingly paradoxical discrepancy between the minted messages and the systematic political, legal, and military invasion on American Indian sovereignty in that period, the paper proceeds to deconstruct the paradox by exposing the numismatic pictorial language as a manifestation of the same ideological project and the configurations of power that have remained unchanged to this day. The continued circulation of indigenousbased iconography in the contemporary American context shows that the same cultural imagination continues to serve not only as a powerful rationale for European America's historical, national, and political narrative but also as a form of "anti-conquest" that both obscures and enacts the established formulas of colonial domination and control. Observing the alterations of the Washington Redsk*ns logo design across some of the key socio-historical moments of the second half of the twentieth and the beginning of the twenty-first century, the analysis explores how various forms of national anxiety transcend into identity through the politics of 
representation. In that light, Runtić and Pejić regard recent activism against massmediated symbolization of indigenous identity as an important arena in which centuries-old hegemonic discourses are contested against new venues of selfdetermination and internal decolonization.

Runtić and Pejić's paper is followed by "'California forgets. Luna remembers:' Sensing contemporary Native American realities in James Luna's performance Native Stories: For Fun, Profit \& Guilt" by Claudine Armand from the University of Lorraine, France. Armand discusses how James Luna's multimedia performances are largely rooted in his culture and daily experience as a Pooyukitchum (Luiseño) Indian living on La Jolla reservation north of San Diego, in Southern California. Informed by a polyphonic style, they interweave, converse, and collide with various personal, collective, fictional, and non-fictional stories and discourses. This fluid and yet fractured approach incorporating visual, aural, written, and body language directly engages contemporary viewers through the resonances and dissonances of present and past, the physical presence of the artist's acting body, and through the immersive environment they are invited to share with the artist in the here-and-now of the performance site. This article is based on the performance Native Stories: For Fun, Profit \& Guilt, which James Luna presented in October 2014 in San Francisco during the Litquake festival, featuring Sheila Tishmil Skinner and followed by a spoken-word monologue by Guillermo Gomez-Peña. It aims to highlight how Luna senses today's Native experience and how he mediates California's present and historical past. The play with metamorphosis, distortion, and dissonances, the slippages in various personae, along with the combination of technology-mediated devices, are some of the strategies he uses to trace the complexities of contemporary indigenous peoples' realities.

In her paper "To Ojibwe country and back: Books and Islands in Ojibwe Country by Louise Erdrich," Marija Krivokapić from the University of Montenegro proposes a close analysis of Erdrich's Books and Islands in Ojibwe Country, which she considers as a piece of travel writing. Krivokapić looks at the book first through the lenses of recent developments in travel writing critical theory. However, the author argues that this theory, being developed on the theoretical tools of postcolonialism, i.e. on problematizing the intentional perception of the Western travelling subject and on questioning this subject's almost innate adoption of hierarchical superiority in relation to the travelling object, cannot vitally apply to another "conceptual reality" in which these relations are nonexistent. She then looks into the feminist reading of contemporary travel writing and concludes that its, often militant, stand does not comply with a culture that knows child bringer and language teacher as a woman. To pay due respect to the text in question, she also turns to some of the Native American authored discussions on the difference of meaning of land in contrast to mapping territory, of understanding the circularity of time in contrast to the linearity of history. Finally, the paper shows how this book of travel defies Theory and develops into a potent response to the dehumanizing semiotics of the Native subject. The book is focused on the reality of people who once painted rocks to tell stories and now write books and own bookshops, who once used cattails as diaper material, but now engage their babies with toy computers while driving them in their vans on highways. It also speaks of a legitimate decision of a female 
intellectual to move and invest in her own kind of the Linnaean enterprise and, by describing the living species of the lake in the Ojibwemowin language, to draw out a special taxonomy, through which her people have always understood themselves and, thus, lay the foundation for development of her own people's discursive ordering.

"Ethnic identity in Thomas King's Green Grass, Running Water" by Jovana Petrovic from the University of Novi Sad, Serbia, analyzes the elements that constitute Native American identity in the said King's novel. In the novel, King juxtaposes two ethnic identities-white Christian American, representing the majority in American society, and Native American, representing a minority. King portrays the struggle of Native Americans in the U.S. and Canada to define their identity given the historically long rift between their Native heritage and the white culture. Stigmatized for their ethnicity and race, Native Americans were exposed to marginalization and prejudice and forced to somehow overcome this position. The struggle has been made more difficult by the efforts of the dominant society to assimilate them and at the same time prevent them from claiming full citizenship. King carefully weaves the stories of his characters, who constantly go back and forth between the reservation lands and the outside world, having to find their position in both and usually not belonging to either. As Petrović shows, by focusing on the world of the reservation, Native American spirituality, tribal tradition of storytelling, and creation myths, King juxtaposes Native American ethnic identity with that of the dominant society in order to reevaluate the marginalized position of the Native Americans.

Tijana Matović from the University of Kragujevac, Serbia, participates with a paper titled "Healing and recuperation in Louise Erdrich's story 'The Bingo Van'." This paper approaches the story from the title as a representative work of the author's long-standing narrative attempt to use gambling as a way of addressing the possibility of change in Native American communities. The protagonist of the story, Lipsha Morrissey, is a psychologically disoriented young Chippewa man, apparently focused on short-term goals, which ultimately reveal themselves as a corrupt version of the illusory American Dream. Lipsha is otherized and, as such, almost without resistance forced to accept the normative stamp of the culture of dominance, as Matović derives relying on Gerald Vizenor's terminology. Lipsha's healing power decreases as he becomes overwhelmed by the materialistic drive fueled by a prominent van-obsession. The sacred place is replaced with a pre-empted one, and it brings about moral devastation to Lipsha. His subsequent recovery progresses within a healing narrative, which brings about a waking-up into a restful nothing-a landscape swept with a blizzard-such an emptiness being vital in what Erdrich shapes as a powerful potential for recuperation.

Milena Kaličanin from the University of Niš, Serbia, moves to Canadian indigenous, social, and literary landscapes and discusses the relation of fact and fiction in Rudy Wiebe's 1974 collection of short stories Where is the Voice Coming From. Kaličanin argues that the mere fact that this collection has seen numerous new editions at the turn of the twenty-first century reflects its credibility in depicting contemporary indigenous phenomena. Apart from exploring the complex relationship of document, history, and fiction, the well-known title story depicts two 
contrasted views on experiencing reality - the one that perceives it as a mysterious, almost mystical experience and is generally related to the oral culture of the indigenous peoples and the other one that rests on the allegedly objective factual evidence of the white settlers. In his exploration of the conflict between "Almighty Voice" and the North West Mounted police, which has been the subject of various conflicting accounts, Wiebe examines the process of turning events into stories and expresses his doubts about their historical accuracy. In that, he comes close to the view of various postcolonial literary critics, who generally oppose the trend of falsifying reality by relying on the objectivity of historical reports as the only way of experiencing and decoding the past.

"The devil's language of Marilyn Dumont" by Vesna Lopičić from the University of Niš, Serbia, discusses another literary and social issue that comes from Canadian ground. The article is meant to be a sort of case study focusing on contemporary indigenous realities as represented in the poetry of Marilyn Dumont. A Really Good Brown Girl is a relatively short collection of poetry published in 1996 by Brick Books. Lopičić was curious to see how much of contemporary indigenous reality will be identifiable in the poems collected in a single book by an author who is widely anthologised but not overwhelmingly popular in Canada. A close reading of her poetry proves that Dumont touches on many aspects of Métis contemporary reality such as the corruption of their culture, the problem of identity, the relationship between the First Nations and the white people, living conditions, gender roles, school system, etc. Support for Dumont's poetic rendering of the realities of indigenous people is found in Thomas King's The Inconvenient Indian and other critical works. Lopičić conludes that social criticism finds its expression in the poetry which is personal and yet a form of resistance writing.

"Part-time identities and full-time narration as an absolution in Alexie's The Absolutely True Diary of a Part-Time Indian" is a paper by the University of Montenegro scholar Vanja Vukićević Garić. As Vukićević argues, belonging to a broad genre of Bildungsroman and a less broad literary form known as fictional diary, this Alexie's young-adult novel explores the implications of self-narration in the context of a painful search for a more unified and solid identity within a fragmented and stereotype-troubled social and political framework. The focus of this paper, therefore, is not only the protagonist's psychological duality, generally inherent to the genre itself, but also the transformative power of the particularly hybrid and culturally pluralistic narrative that, in this case, effectively combines Native American and Anglo-European traditions. Drawing on the basic features of diary as a form of intensely autobiographical writing, the paper aims at pointing to its multiple therapeutic forces, as well as to the phenomenological importance of self-expression in artistic, political, and existential terms.

As this selection of papers from the Contemporary Indigenous Realities conference comprises contributors from a number of universities from Europe and the U.S., a variety of current theoretical perspectives that encompass postmodern, postcolonial, and poststructuralist approaches, as well as the disciplines of Canadian, American, and American Indian Studies, we hope that it will attract an expanding audience, provide fruitful ground for further investigations in these fields, and instigate new challenging debates within interdisciplinary scholarship. 